Article

\title{
Detecting and Quantifying a Massive Invasion of Floating Aquatic Plants in the Río de la Plata Turbid Waters Using High Spatial Resolution Ocean Color Imagery
}

\author{
Ana I. Dogliotti ${ }^{1,2}, *$ (D) Juan I. Gossn ${ }^{1,2}$, Quinten Vanhellemont ${ }^{3}$ and Kevin G. Ruddick ${ }^{3}$ \\ 1 Facultad de Ciencias Exactas y Naturales, Universidad de Buenos Aires, Buenos Aires C1428EGA, \\ Argentina; gossn@iafe.uba.ar \\ 2 Instituto de Astronomía y Física del Espacio (IAFE), CONICET-Universidad de Buenos Aires, \\ Buenos Aires C1428EGA, Argentina \\ 3 Royal Belgian Institute of Natural Sciences (RBINS), Operational Directorate Natural Environment, \\ 1200 Brussels, Belgium; qvanhellemont@naturalsciences.be (Q.V.); kruddick@naturalsciences.be (K.G.R.) \\ * Correspondence: adogliotti@iafe.uba.ar; Tel.: +54-11-5285-7873
}

Received: 20 May 2018; Accepted: 16 July 2018; Published: 19 July 2018

\begin{abstract}
The massive development of floating plants in floodplain lakes and wetlands in the upper Middle Paraná river in the La Plata basin is environmentally and socioeconomically important. Every year aquatic plant detachments drift downstream arriving in small amounts to the Río de la Plata, but huge temporary invasions have been observed every 10 or 15 years associated to massive floods. From late December 2015, heavy rains driven by a strong El Niño increased river levels, provoking a large temporary invasion of aquatic plants from January to May 2016. This event caused significant disruption of human activities via clogging of drinking water intakes in the estuary, blocking of ports and marinas and introducing dangerous animals from faraway wetlands into the city. In this study, we developed a scheme to map floating vegetation in turbid waters using high-resolution imagery, like Sentinel-2/SMI (MultiSpectral Imager), Landsat-8/OLI (Operational Land Imager), and Aqua/MODIS (MODerate resolution Imager Spectroradiometer)-250 m. A combination of the Floating Algal Index (that make use of the strong signal in the NIR part of the spectrum), plus conditions set on the RED band (to avoid misclassifying highly turbid waters) and on the CIE La* ${ }^{*}$ color space coordinates (to confirm the visually "green" pixels as floating vegetation) were used. A time-series of multisensor high resolution imagery was analyzed to study the temporal variability, covered area and distribution of the unusual floating macroalgae invasion that started in January 2016 in the Río de la Plata estuary.
\end{abstract}

Keywords: floating vegetation; turbid water; Río de la Plata; aquatic macrophytes; Sentinel-2; Landsat-8; Aqua

\section{Introduction}

Water hyacinth (Eichhornia crassipes) is a free-floating macrophyte native to Lower Amazonia, Brazil, that forms dense mats on the surface of slow-moving waterways and backwaters. In floodplain wetlands aquatic macrophytes play a crucial role since they take part in life cycles of several other species providing food, nesting sites, refuge, etc., and can also interact with other factors modifying some physical and chemical characteristics of the environment, such as the transparency of water, sedimentation rates, etc. [1]. On the other hand, massive proliferation of the invasive water hyacinth might represent a significant threat to recreation, fisheries, and wildlife resources, and ecological 
processes of freshwater ecosystems, like in lake Victoria in East Africa [2], the Río Grande River [3], and in California's Sacramento-San Joaquin River Delta [4] in the United States.

Mapping of aquatic plants and estimation of their surface extent are crucial to the efficient management and implementation of mitigation measures. This information can be derived accurately with fine resolution remote sensing products like the high resolution imagery provided by Sentinel-2/MSI (10 m) and Landsat-8/OLI (30 m) systems, but their low observation frequency and narrow swath hinder their ability to continuously monitor and quantify the extent of floating vegetation. Meanwhile coarser resolution sensors, like MODIS (250 m), OLCI (300 m), and PROBA-V (100 m) provide a wider view and higher data frequency, but at the expense of spatial details. Different indexes have been developed to detect floating aquatic vegetation using remote sensing data that make use of their strong near infrared (NIR) reflectance similar to that of land vegetation [5-11]. These indexes have been originally mainly for clear waters, but their applicability in turbid waters is not straightforward as has been already mentioned in [12] and further analyzed in [13].

In the Paraná River floodplain in Argentina (Figure 1), floating aquatic vegetation represents an important biomass, mobilized by flood pulses and climatic factors, and its drift moves organic matter, insects and other organisms in the ecological system. Aquatic plant detachments drift downstream arriving in small amounts to the Río de la Plata (RdP) every year, but massive temporary invasions have been observed in the RdP every 10 or 15 years. In mid-January 2016 the coast of Buenos Aires became covered with large mats of the aquatic hyacinth Eichhornia crassipes. This extraordinary event was related to unusually heavy rains that occurred in Southern South America at the end of 2015 associated to a strong El Niño that flooded the rivers that feed into the Río de la Plata. The rain and floods raised water levels of the floodplains along the Paraná river and swept floating plants into the main river waterway (Figure 1b). This massive temporary invasion of aquatic plants that occurred from January to end of April 2016 caused significant disruption of human activities via clogging of drinking water intakes in the estuary, blocking of ports and marinas and introducing dangerous animals from faraway wetlands into the city.
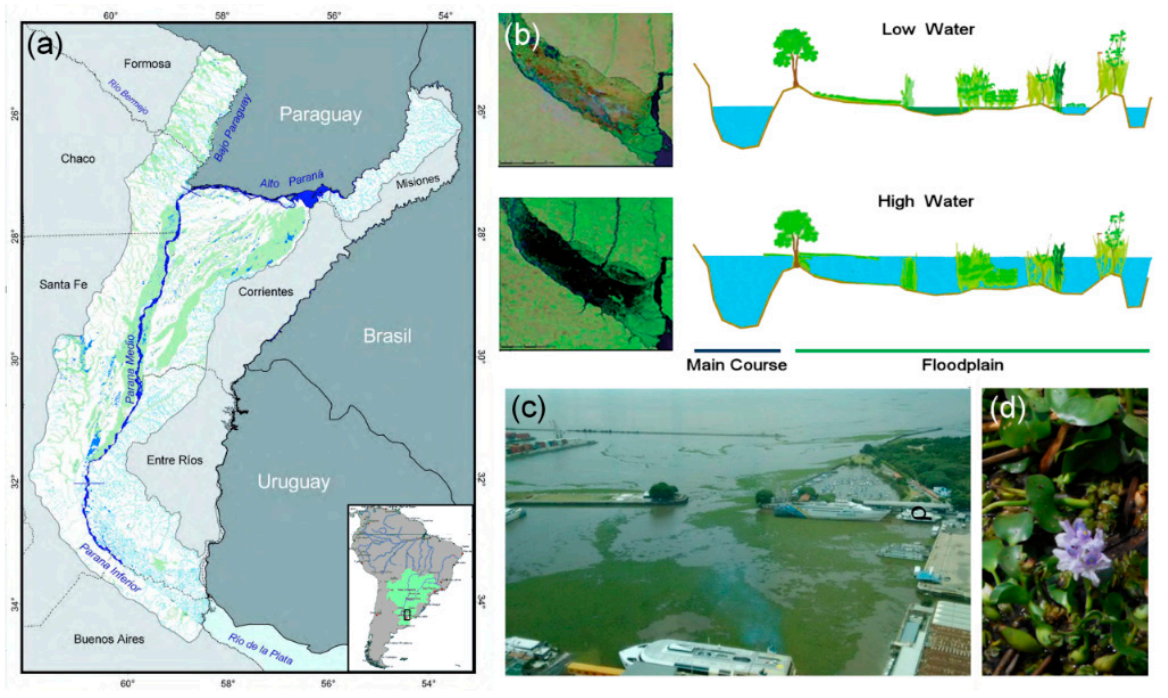

Figure 1. (a) Location of the Paraná-Paraguay fluvial corridor and Río de la Plata estuary; (b) schematic representation of low and high water conditions (water pixels are dark-blue in the Red-Green-Blue Landsat images of the Paraná delta) that can be found in the floodplain (modified from [14]); (c) a passenger ferry terminal invaded by water hyacinth (d).

The objective of the present study is to assess the unusual invasion of Eichhornia crassipes in the Río de la Plata in a multimission perspective. A methodology is developed using a set of indexes and conditions to detect the presence of the water hyacinth in the RdP turbid waters using Sentinel-2A/MSI, 
Landsat-8/OLI, and Aqua/MODIS-250 m imagery. The impact of different spatial resolution on the FV detection is discussed. Finally, the spatial extension is quantified and its temporal variability analyzed and related to the river outflow.

\section{Study Area}

La Plata basin is the second largest basin in South America after the Amazon and the fifth largest in the world [15]. It drains to the Atlantic Ocean at around $34^{\circ} S$ through the Paraná and Uruguay rivers (Figure 1). The Paraná river supplies most of the sediment load reaching the Río de la Plata estuary, most of which originates in the Bermejo river, amongst the most turbid rivers of the world $\left(\sim 8000 \mathrm{~g} \mathrm{~m}^{-3}\right)$. The La Plata also drains around 79\% of the discharged water, which has annual mean flow rate of $\sim 22,500 \mathrm{~m}^{3} \mathrm{~s}^{-1}$, but can reach up to $\sim 90,000 \mathrm{~m}^{3} \mathrm{~s}^{-1}$ and can be as low as $\sim 7800 \mathrm{~m}^{3} \mathrm{~s}^{-1}$ in association with the El Niño Southern Oscillation (ENSO) cycle [16,17]. The Paraná-Paraguay fluvial corridor starts in tropical latitudes (Pantanal in Brazil), runs through subtropical regions and ends in the Río de la Plata estuary, located in a temperate region. It is the main surface water collector of the basin and has a high extent of wetlands characterized by a regime of drought and flood pulses [18]. This biogeographical corridor constitutes an effective route for passive or active migration of flora and fauna from tropical to temperate zones [19]. The main water collectors (Paraguay and Paraná) present branched watersheds over complex flood plains [14]. The end portion of the Paraná-Paraguay fluvial corridor is characterized as a wetland macrosystem [20], the Paraná Delta where the Paraná river converges with the Uruguay river into the Río de la Plata estuary. This large funnel shape estuary has significant social, ecological and economical importance for the countries on its shores, Argentina and Uruguay. The capital cities of both countries (Buenos Aires and Montevideo) and a number of harbors, resorts, and industrial centers are located on its margins and influence zone. The estuary constitutes the main source of drinking water for the millions of inhabitants in the region, for whom it is also an important recreational area.

\section{Materials and Methods}

\subsection{Satellite Data}

Satellite data with different spatial and temporal resolutions covering the RdP region from the 2015-2016 period were used in the present study (Table 1). MODIS-Aqua (MA) L1A images were downloaded from the NASA Ocean Color web site (http:/ / oceancolor.gsfc.nasa.gov), orthorectified and terrain corrected Landsat-8/OLI (L8) L1T files from USGS EarthExplorer (http: / / earthexplorer. usgs.gov) and Sentinel-2A/MSI (S2A) L1C files from the European Space Agency /ESA) Copernicus Open Access Hub (https:/ / scihub.copernicus.eu).

Table 1. List of the systems used in this study, their spatial resolution, center wavelength (in nm) and bandwidth (BW) of the bands used to identify FV, swath and revisit time.

\begin{tabular}{|c|c|c|c|c|c|c|c|c|}
\hline & $\begin{array}{c}\text { Spatial } \\
\text { Resolution (m) }\end{array}$ & $\begin{array}{l}\text { RED } \\
\text { (BW) }\end{array}$ & $\begin{array}{l}\text { GREEN } \\
\text { (BW) }\end{array}$ & $\begin{array}{l}\text { BLUE } \\
\text { (BW) }\end{array}$ & $\begin{array}{l}\text { NIR } \\
(\text { BW) }\end{array}$ & $\begin{array}{l}\text { SWIR } \\
\text { (BW) }\end{array}$ & $\begin{array}{c}\text { Swath } \\
(\mathbf{k m})\end{array}$ & Revisit \\
\hline MODIS/Aqua & $250^{1} \& 500^{2}$ & $\begin{array}{l}645^{1} \\
(50)\end{array}$ & $\begin{array}{c}555^{2} \\
(20)\end{array}$ & $\begin{array}{l}469^{2} \\
(20)\end{array}$ & $\begin{array}{l}859^{1} \\
(250)\end{array}$ & $\begin{array}{c}1240^{2} \\
(20)\end{array}$ & 2330 & Daily \\
\hline L8/OLI & 30 & $\begin{array}{l}655 \\
(50)\end{array}$ & $\begin{array}{l}561 \\
(75)\end{array}$ & $\begin{array}{l}483 \\
(65)\end{array}$ & $\begin{array}{l}865 \\
(40)\end{array}$ & $\begin{array}{l}1650 \\
(100)\end{array}$ & 180 & $\begin{array}{c}8 \text { or } 16 \\
\text { days }\end{array}$ \\
\hline $\mathrm{S} 2 \mathrm{~A} / \mathrm{MSI}$ & $10^{3} \& 20^{4}$ & $\begin{array}{l}665^{3} \\
(30)\end{array}$ & $\begin{array}{l}560^{3} \\
(35)\end{array}$ & $\begin{array}{l}497^{3} \\
(65)\end{array}$ & $\begin{array}{c}865^{4} \\
(20)\end{array}$ & $\begin{array}{c}1610^{4} \\
(90)\end{array}$ & 290 & 10 days \\
\hline
\end{tabular}

Rayleigh-corrected reflectance $\left(R_{r c}\right)$ at all bands was obtained using different freely available software for the different sensors: MODIS data was processed using SeaDAS v7.4, and OLI and MSI data were processed using ACOLITE (Atmospheric Correction for OLI 'lite') software 
v.20170718.1 [21,22]. RGB "true-color" images were also generated for each sensor using the corresponding red $(R)$, green $(G)$ and blue $(B)$ band of each sensor (see Table 1). MODIS-Aqua daily images were mapped to a cylindrical equidistant projection at $0.002^{\circ}$ spatial resolution $(\sim 250 \mathrm{~m})$.

\subsection{Field Data}

Surface reflectance measurements were made on a dense mat of aquatic hyacinth during the invasion on 28 January 2016, from a pier located in the city of Tigre, to the north of Buenos Aires city and close to the Paraná Delta. Two Trios-RAMSES hyperspectral spectroradiometers, measuring radiance and downwelling irradiance, were mounted on a custom-made frame. Zenith angle of the sea-viewing radiance sensor was $40^{\circ}$ and the azimuth angle from the sun was varied slightly around $135^{\circ}$ (the sun was occluded by clouds though still visible). Spectral reflectance $\left(\rho_{w}\right)$ was calculated as $\pi$ times the upwelling radiance divided by the downwelling irradiance. Sky radiance was also measured but no correction was made for air-water interface reflection of sky radiance because most of the surface was covered by vegetation.

The measured spectral reflectance of the aquatic hyacinth is compared with existing water reflectance spectra collected between 2012 and 2016 during several campaigns and in different regions of the RdP. During these field campaigns the measured turbidity and total suspended matter ranged between 35-200 FNU (Formazin Nephelometric Units) and 25-115 mg/L, respectively. Part of this data set has been used previously for validation and algorithm development [23,24].

\section{Results and Discussion}

\subsection{Spectral Features of Eichhornia Crassipes}

Surface reflectance from Eichhornia crassipes mats were collected close to Buenos Aires during the floating vegetation invasion in January 2016 (Figure 2). Spectra showed typical spectral features of aquatic macrophytes, i.e., a marked increase of reflectance in the NIR (700-900 nm), mainly due to cellular structure of the leaves in the specific case of E. crassipes, and a peak in the green region $(\sim 550 \mathrm{~nm})$ due to absorption of chlorophyll-a in the blue and red $(675 \mathrm{~nm})$ parts of the spectrum (green spectra in Figure 2). This increase in reflectance in the NIR, known as the red-edge reflectance, can also be caused by other organisms or material floating on the surface, such as floating seagrass and the accumulation of cyanobacterial cells in the surface forming dense mats, known as scum, that reduce the absorbing effect of water. The nine measurements performed pointing the radiometer in slightly different azimuth angles close to $135^{\circ}$ showed higher variability in the NIR region (dashed green lines). This is probably due to the different percentage of area covered by vegetation and water given the inhomogeneous and moving nature of target (Figure 2) as well as possible directional (azimuthal) dependence for the reflectance of vegetation. For comparison the mean (bold) and plus/minus one standard deviation (dashed) spectra of more than 50 field measurements collected in the RdP turbid waters are shown in black in Figure 2. The mean spectra of the turbid waters shows typical features that are expected in the upper estuary (close to Buenos Aires), i.e., low reflectance in the blue region due to absorption of dissolved and particulate matter, a main peak reflectance at around $700 \mathrm{~nm}$ (varying between 550 and $700 \mathrm{~nm}$ with particle concentration) and a second peak around $810 \mathrm{~nm}$ due to backscattering of particles where pure water absorption has a local minimum [25]. 


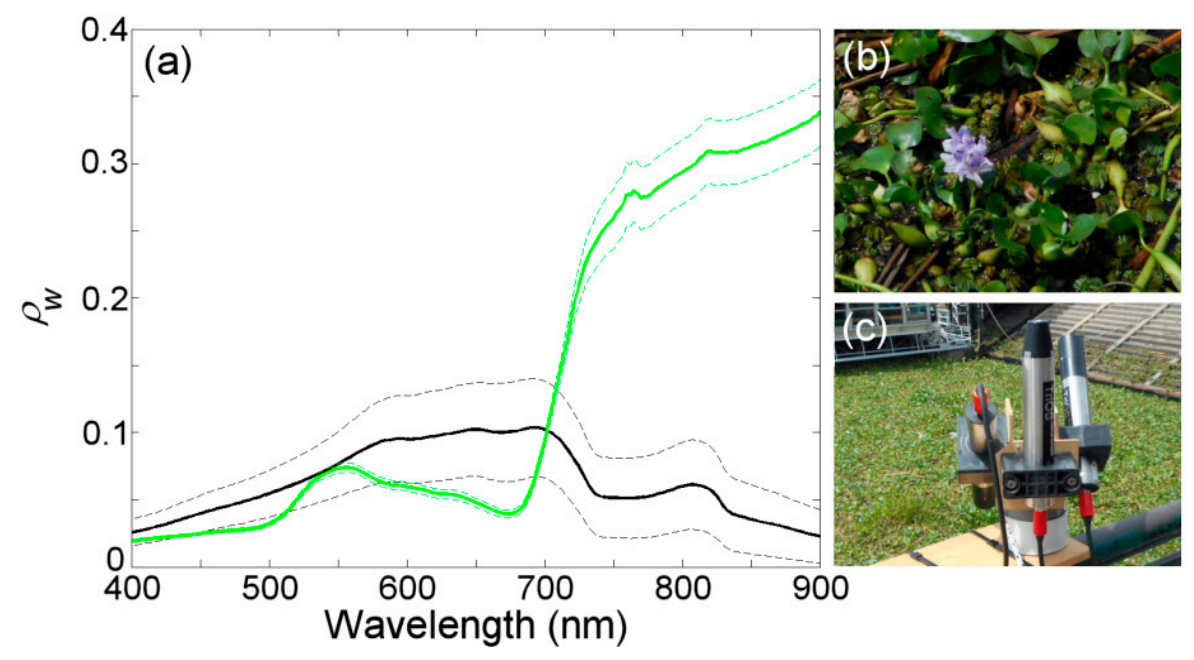

Figure 2. (a) In situ reflectance spectra of water hyacinth mats (green) collected in January 2016 and RdP turbid waters (black) collected in previous cruises. Thick lines represent the mean of 9 and $>50$ measurements from Eichhornia crassipes mats and turbid waters of RdP, respectively. Dashed lines correspond to one standard deviation. Photographs of (b) floating water hyacinth E. crassipes, and (c) measurement setup.

\subsection{Floating Vegetation Identification}

The detection of floating macroalgae using remote sensing has been usually performed using indexes that make use of their strong signal in the near infrared (NIR) and short-wave infrared (SWIR), which is similar to that of land vegetation and contrasts highly with the low signal coming from the water. One example is the normalized difference vegetation index (NDVI). In order to detect E. cressipes in the highly turbid waters of Río de la Plata estuary, a combination of different indexes and thresholds have been used which are described in this section.

The floating algal index (FAI), which has been used to detect floating algae due to the enhanced reflectance in the NIR [26], is defined as

$$
\mathrm{FAI}=R_{r c}^{N I R}-\left[\frac{R_{r c}^{R E D}\left(\lambda_{N I R}-\lambda_{S W I R}\right)+R_{r c}^{S W I R}\left(\lambda_{R E D}-\lambda_{N I R}\right)}{\left(\lambda_{R E D}-\lambda_{S W I R}\right)}\right]
$$

where $\lambda_{\text {band }}$ is the central wavelength in each band (RED, NIR, SWIR) corresponding to the sensor (Table 1). The FAI is calculated as the difference between $R_{r c}$ in the NIR and the baseline (linear interpolation) between the reflectance in the RED and SWIR bands (Figure 2). In general, positive values of FAI indicate presence of floating vegetation.

In the most turbid part of the estuary (in the maximum turbidity zone), reflectance is very high in the NIR (high concentration of particles) and lower in the RED and SWIR bands (high water absorption) thus giving a peak in the NIR which is erroneously interpreted as a floating vegetation pixel by the FAI (brown spectra in Figure 3). In order to avoid these false positives in the most turbid waters, a threshold on the red band was determined. In low-to-moderate turbid waters, a threshold in the SWIR band would be useful, but due to the contribution from aerosols, sunglint, and high amount of sediments affecting MODIS $1240 \mathrm{~nm}$ band [7], similar Rayleigh-corrected water reflectance values have been found for very turbid waters and floating vegetation. In turn, the red band is affected by chlorophyll- $a$ absorption of the floating vegetation (decreasing reflectance) and by particle scattering for increasing turbidity (increasing reflectance). The threshold was defined by analysis of a 2-year time series of images over the region of highest turbidity in the following [13]. Thus, a threshold of 0.08 in the Rayleigh-corrected reflectance in the RED was set to differentiate highly turbid water pixels from vegetated pixels. 


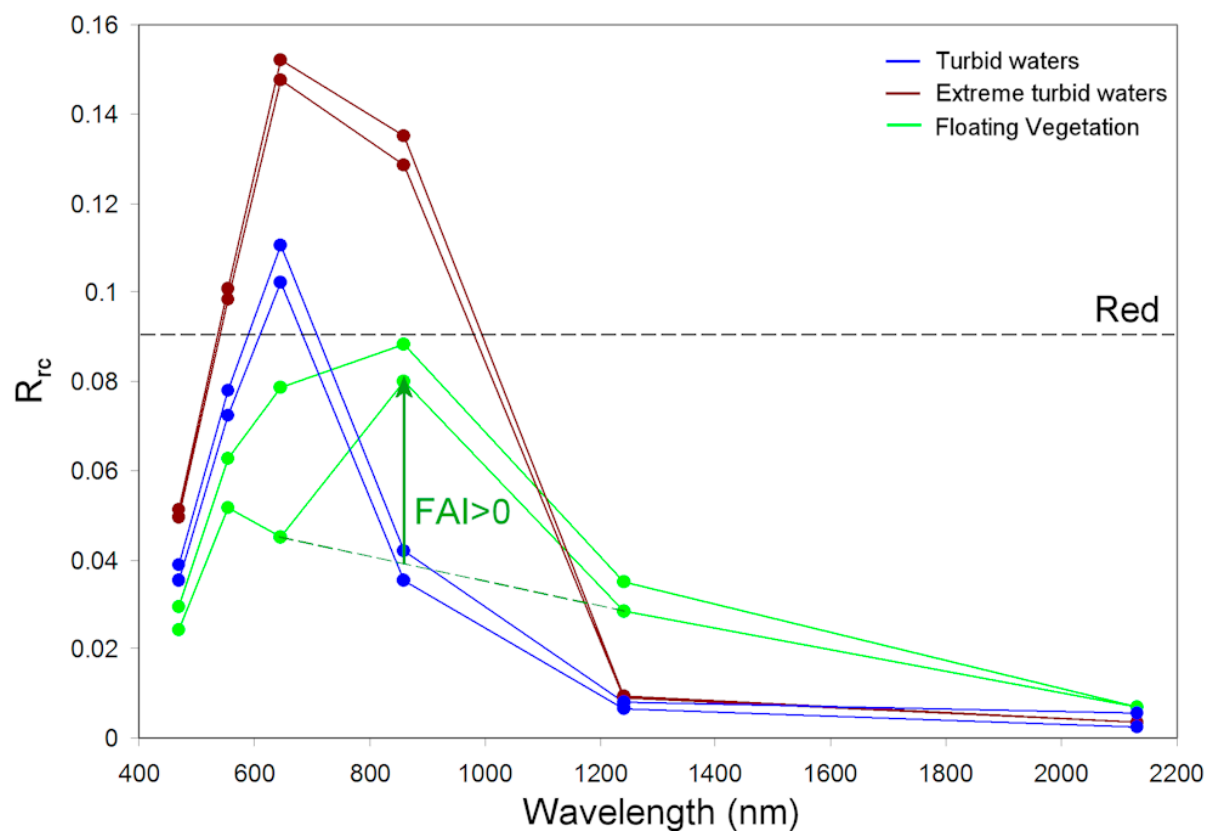

Figure 3. Rayleigh-corrected spectra of pixels that look green in the RGB combination thus containing a detectable amount of floating vegetation (green), turbid (blue) and extreme turbid (brown) waters extracted from MODIS-Aqua image of the RdP estuary. The FAI index is schematically indicated as well as the threshold applied to the $R_{r c}$ in the RED band.

Additional criteria were set to differentiate floating vegetation from other above-surface targets like ships, regions of above-surface sediment accumulations, and cloud edges, which were clearly not vegetation by visual inspection of the RGB composites. Given that visual inspection is the only way to validate the results, the CIE $1976 \mathrm{Lab}$ (from now on, $\mathrm{La}^{*} \mathrm{~b}^{*}$ ) [27] color space metrics were used to quantify the differences in color as perceived by humans. La*b* is a three dimensional space, equivalent to RGB, described by the color variables $\mathrm{L}$, $\mathrm{a}^{*}$ and $\mathrm{b}^{*}$ which are isomorphic to RGB. Basically, $\mathrm{L}$ stands for luminosity, and takes values from 0 (absolute black) to 100 (absolute white), while $\mathrm{a}^{*}$ separates green $\left(a^{*}<0\right)$ from red $\left(a^{*}>0\right)$, and $b^{*}$ separates blue $\left(b^{*}<0\right)$ from yellow $\left(b^{*}>0\right)$. The isomorphism that defines it from RGB color space is a non-linear transformation and is thoroughly described at [27]. The $\mathrm{La}^{*} \mathrm{~b}^{*}$ variables were calculated by applying the color.rgb2lab function from Python module skimage to the RGB matrix defined as a combination of Rayleigh-corrected reflectances in the RED, GREEN and BLUE (Table 1), normalized to a maximum threshold of 0.12 to enhance the color contrast of non clouded targets. Given that floating vegetation pixels can be identified by their greenish color, a condition on the upper limit of $\mathrm{a}^{*}$ was set. Thresholds on $\mathrm{a}^{*}$ were empirically determined by visual inspection for each sensor: 0 for S2, 5 for L8 and 10 for MA. This condition helps excluding targets such as ships and above-surface sediment accumulation and some cloud edge pixels mainly in high resolution imagery like L8 and S2A (Figure 4). Different a* thresholds were applied to different sensors mainly because (i) RGB composites are defined using band triplets that possess different spectral characteristics, meaning different color appearance for each sensor, and (ii) different resolutions might convey different color signatures according to the covered area (see next section). To avoid further false positives usually located in cloud edge pixels with highly variable spectral characteristics and apparent color, clouds were masked when $\mathrm{L}=100$ and the mask was spatially extended by a given number of pixels that varied for each sensor (10, 5 and 6 pixels for S2A, L8 and MA, respectively). Notice that the condition of $L=100$ is equivalent to the condition $\min (R, G, B)>0.12$, since 0.12 was the normalization factor applied to all RGB composites. 

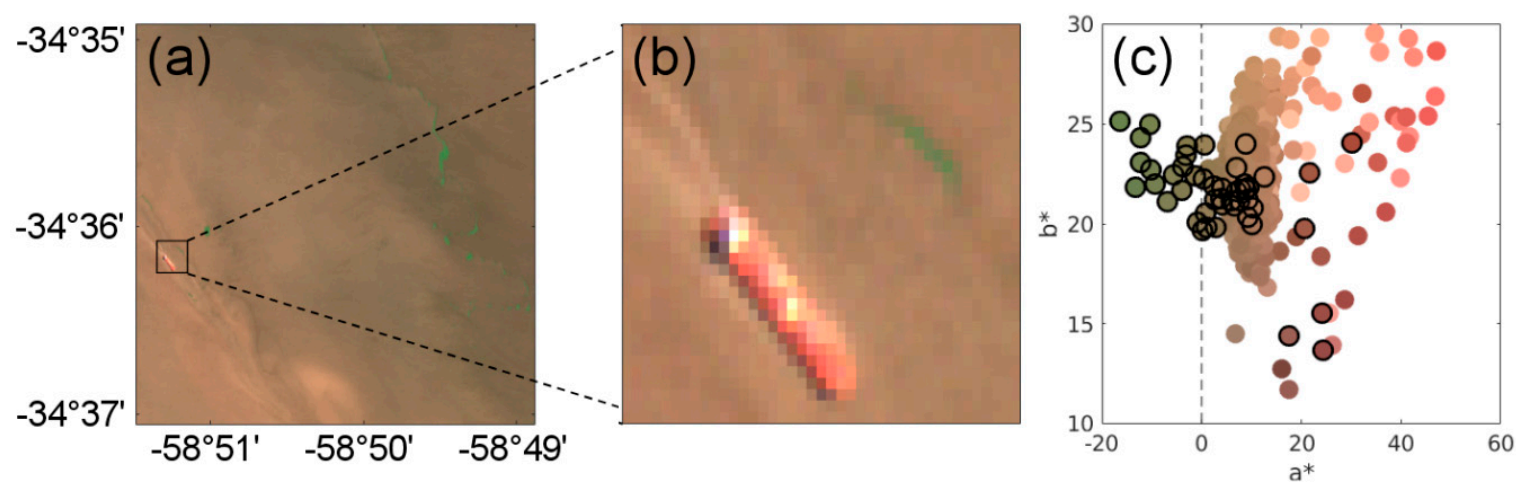

Figure 4. (a) Subset of S2 imagery (9 February 2016) and (b) zoom over a patch of floating vegetation and passing ship; (c) $a^{*}$ vs. $b^{*}$ diagram of the pixels in $\mathbf{b}$ ) colored with the RGB values. Pixels that passed the first spectral criteria (FAI $>0$ and RED $>0.09$ ) are indicated with black contour, while the dashed line indicates the $\mathrm{a}^{*}$ threshold used to further determine the presence of FV.

\subsection{Classification Method Applied in the RdP Estuary}

In a first analysis, the ability of NDVI [7] and FAI indexes to detect the aquatic hyacinth invasion in the RdP was evaluated [28]. Similar the results of $\mathrm{Hu}$ [6], we found that NDVI systematically identified as floating vegetation fewer pixels compared to FAI and a visual analysis indicated that NDVI was more conservative while FAI identified the pixels that an observer would identify as "greenish" or vegetation-containing pixels (Figure 5). This and the fact that FAI is less affected than NDVI by atmospheric effects like aerosols and observing conditions [6], led to selection of the FAI for use in the present study.
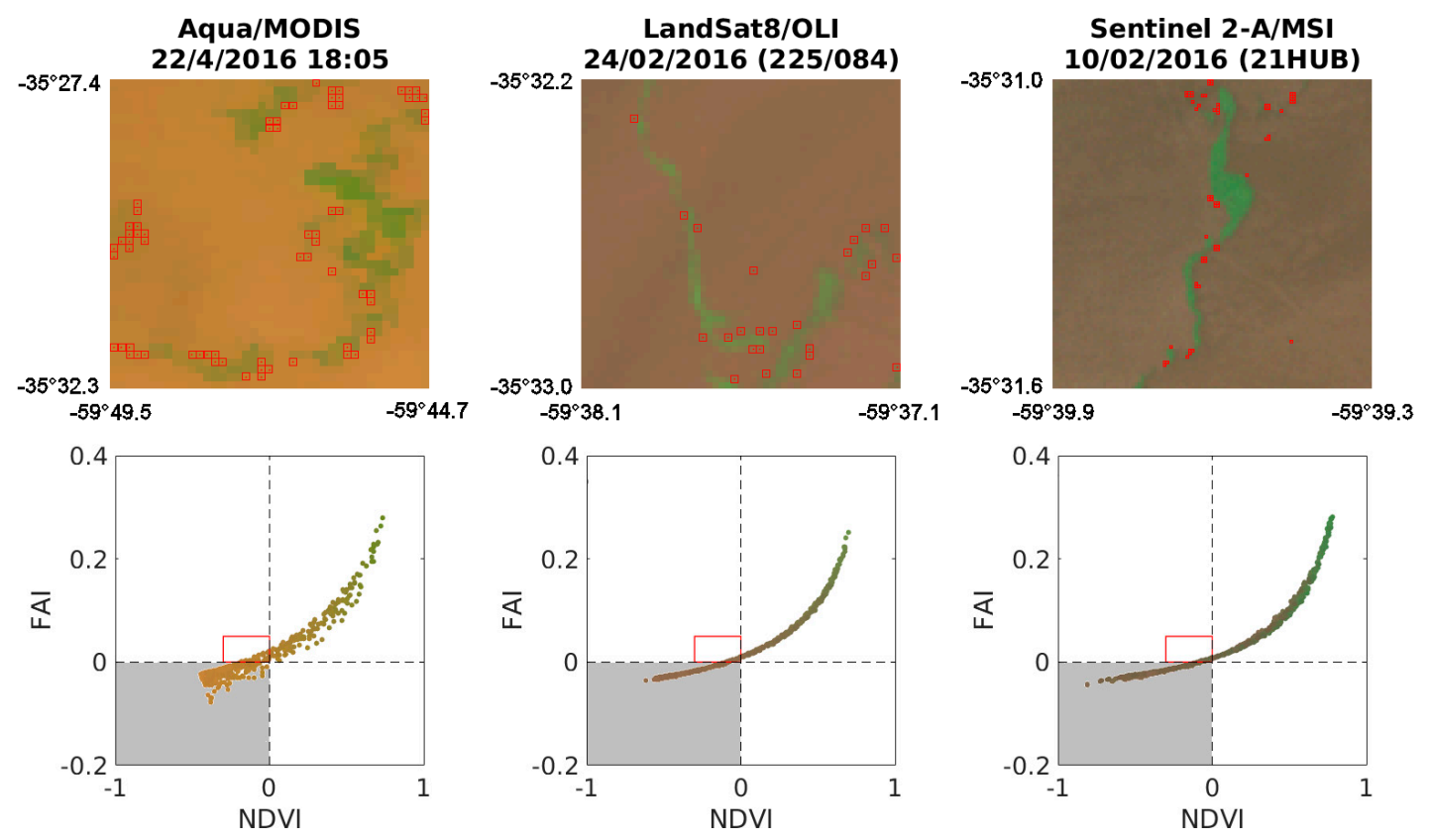

Figure 5. RGB details of floating vegetation (FV) patches for different systems and dates are shown in the (upper row). Red squares indicate the pixels that are flagged as FV by FAI but not by NDVI, also indicated by the red square area in the NDVI vs. FAI scatter plots (lower row). The grey area corresponds to the pixels not identified as FV neither by FAI nor NDVI.

The scheme developed in this study to detect the massive invasion of floating vegetation in the $\mathrm{RdP}$ estuary is outlined in Figure 6. A given pixel is classified as covered by floating vegetation in 
turbid waters, called FAIT, if FAI $>0, R_{r c}\left(\right.$ RED) $<0.08$ and $a^{*}$ is lower than a threshold which varied for each sensor. This algorithm also detects vegetation on land to limit the detection to only floating (and occasionally emerged) vegetation. A multitemporal analysis could be added to the present approach by removing pixels that are persistently detected as vegetation; i.e., to develop a land mask. A robust land masking is required for global application of this method, the development of which is beyond the scope of the present study. Given the complexity of dynamic aquatic environments like river deltas with the presence of temporary land features like intertidal flats and occasionally flooded land and islands, a regionally optimized method may be required.

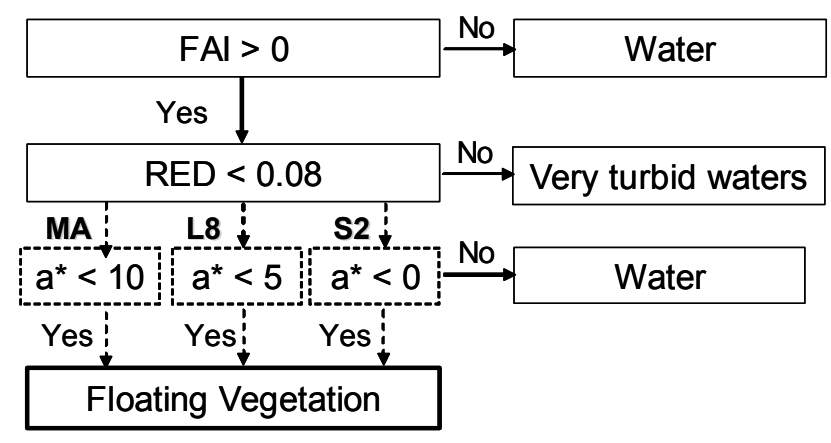

Figure 6. Flowchart of the FAIT scheme used to detect floating vegetation in the turbid waters of RdP estuary.

\subsection{Impact of Spatial Resolution on the FV Detection}

In general, higher spatial resolution imagers were able to detect a larger area covered by floating vegetation and also could resolve finer scale features lost in the coarser MODIS resolution images $(250 \mathrm{~m})$. The detection capability of different high resolution imagers was analyzed and compared to MODIS-Aqua imagery acquired the same day. Several fine scale patches and filaments of floating vegetation have been identified on 24 February 2016 by L8 (Figure 7). Considering the same sub-region in both images (dashed square) the area covered by the identified floating vegetation (calculated multiplying the number of flagged pixels times the nominal surface of the pixel) for L8 (30 m) and MODIS-Aqua $(250 \mathrm{~m})$ was $5.8 \mathrm{~km}^{2}$ and $0.48 \mathrm{~km}^{2}$, respectively. In turn, S2A captured several very small patches $\left(0.24 \mathrm{~km}^{2}\right)$ on 9 February 2016, while for MODIS-Aqua $(250 \mathrm{~m})$ imagery of the same day no floating vegetation was detected (Figure 7). Part of the differences between images of the same day from different sensors are expected due to the difference in time of the satellite overpasses $(\sim 4 \mathrm{~h})$, but mainly due to the reduction of the spectral contrast caused by the lower spatial resolution. The example above clearly shows that if the size of the FV patches is small compared to the spatial resolution of the sensor, the FV covered area could be underestimated or not detected at all.

To assess the impact of varying spatial resolution on the FV detection capability, S2A data $(10 \mathrm{~m})$ was spatially averaged to coarser grids and spectra were extracted from S2A data and averaged over spatial windows corresponding to different resolutions. Figure 8 shows S2 data (9 February 2016) over a patch of floating vegetation at the original resolution $(10 \mathrm{~m})$ and spatially averaged to 30,300 and $1000 \mathrm{~m}$, and the corresponding spectra. This figure shows the loss in spectral contrast as a result of a reduced spatial resolution thus limiting the capability of the coarser resolution sensors to detect floating vegetation. In this case the reflectance corresponding to the pixel of $1000 \mathrm{~m}$ spatial resolution would not be classified as covered by floating vegetation following FAIT scheme given that FAI is negative (Figure 4). 
RGB

24 Feb 2016
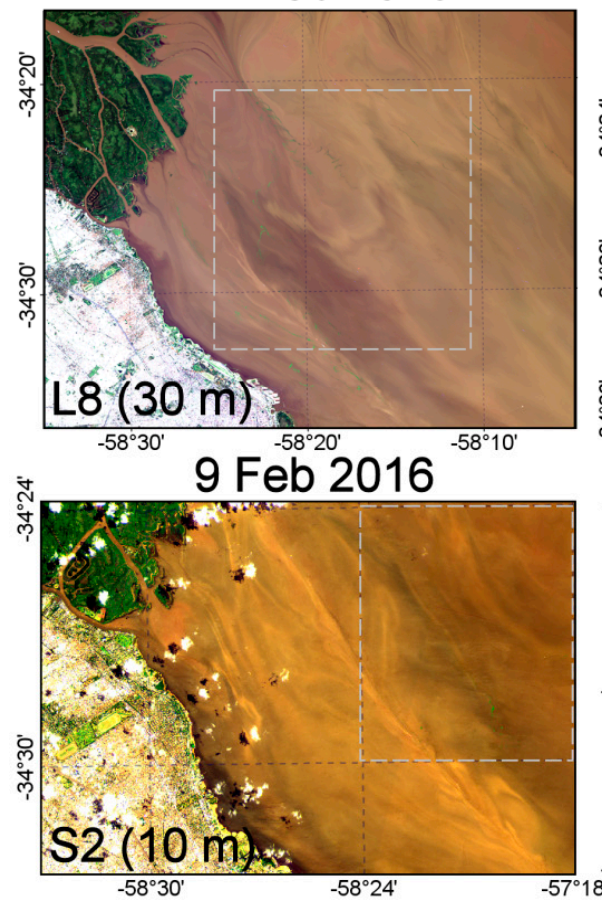

FLOATING VEGETATION
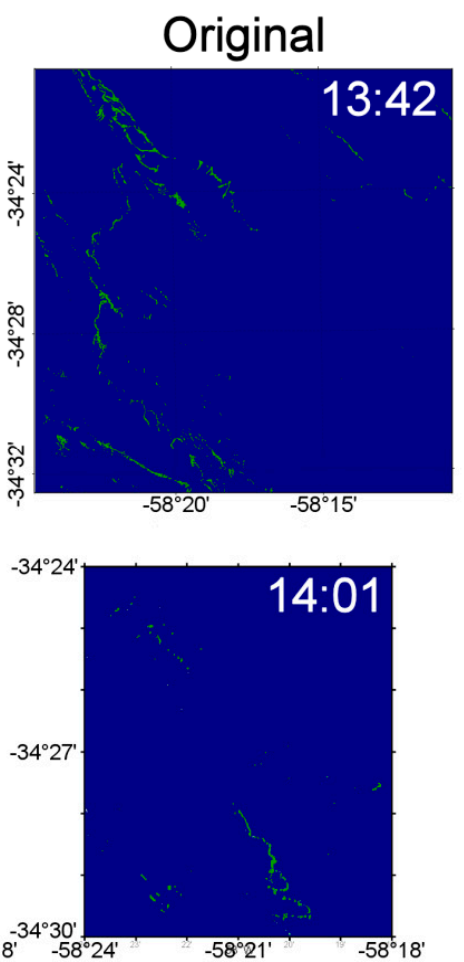

Aqua $(250 \mathrm{~m})$
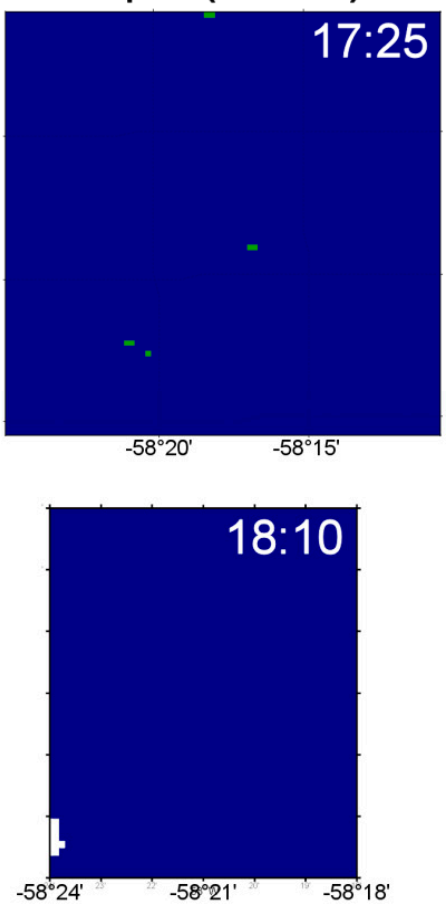

Figure 7. Quasi-true-color red-green-blue (RGB) images from L8 and S2A (left) and pixel flagged as floating vegetation are shown for a subset of each image (dashed squares in RGB) and from the same day MODIS-Aqua image. The acquisition date and time (UTC) of each image is also indicated.
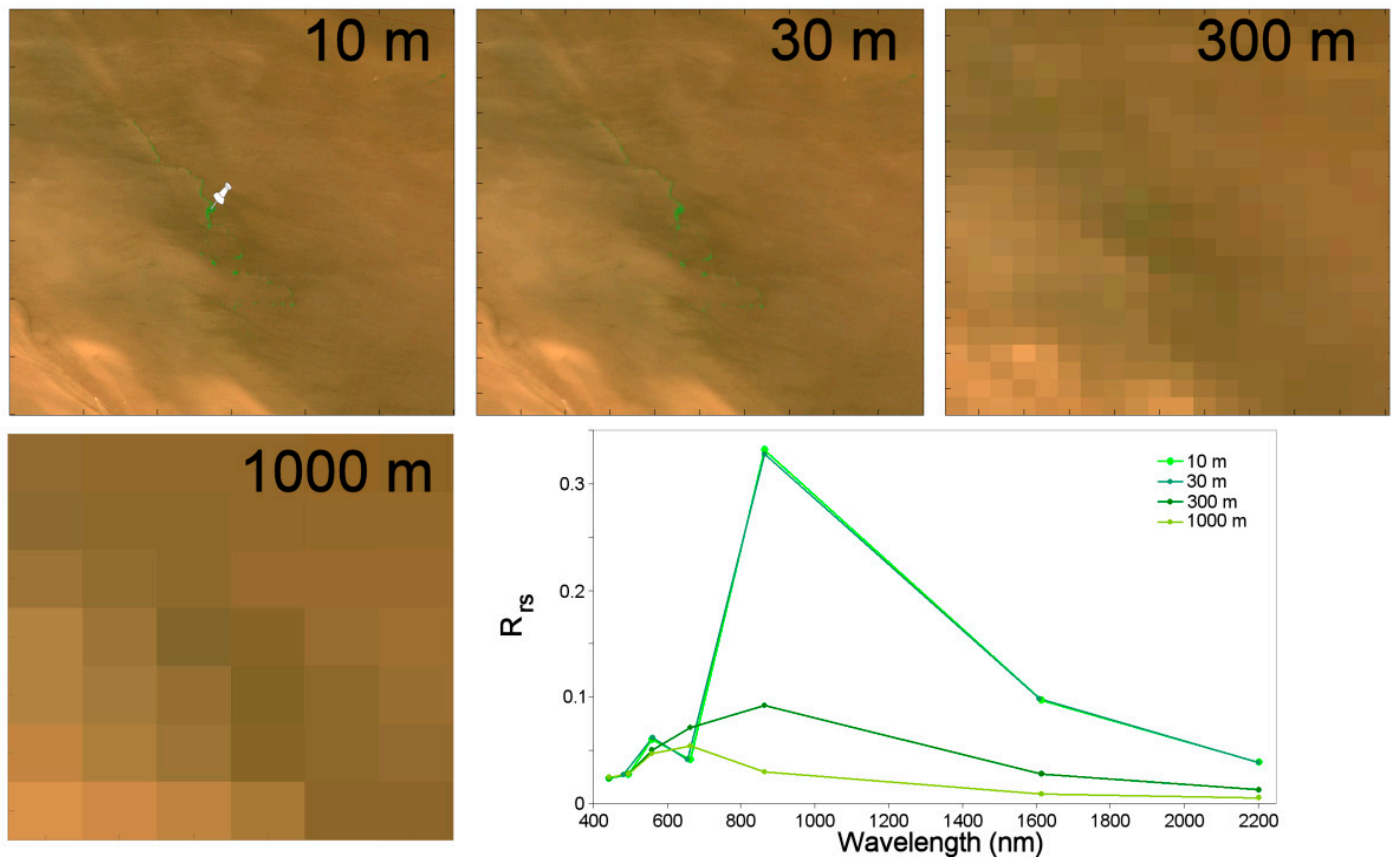

Figure 8. Quasi-true-color S2A data on 9 February 2016 over a patch of floating vegetation (upper left) and spatially averaged to 30,300 and $1000 \mathrm{~m}$ pixel size. Corresponding spectra of the original S2A green pixel and the arithmetic mean value of $3 \times 3,29 \times 29$ and $99 \times 99$ pixel boxes (lower right). 
This is in accordance with previous studies that also suggested that the primary key and limiting factor for mapping floating vegetation patches is the spatial resolution of the sensors $[6,29,30]$. The higher spatial resolution of land-designed L8 and S2 bands increases their capability of detecting FV compared to MODIS-250 m bands, despite their lower sensitivity [6]. In order to estimate the spatial detection limit of the proposed scheme and its variation with water turbidity, i.e., the minimum percentage of $\mathrm{FV}$ at the sub-pixel scale required to be detectable, was calculated by mixing in different proportions endmembers corresponding to FV and water with different turbidities. Similar to the analysis performed by $\mathrm{Hu}$ et al. [12], simulated pixels spectra $\left(R_{S}\right)$ were obtained using different proportions $(P$, varying from 0 to 1$)$ of $\mathrm{FV}\left(R_{F V}\right)$ and water $\left(R_{w}\right)$ reflectance spectra following

$$
R_{s}=R_{F V} \cdot P+R_{w} \cdot(1-P)
$$

The endmembers were selected from different $\mathrm{S} 2 R_{r c}$ images and are shown in Figure 9. A typical FV spectra was obtained from S2 collected on 9 February 2016 (see Figure 7) and four water spectra were obtained from different images taking into account different conditions: TW) turbid waters with typical turbidity values of $\sim 120$ FNU in the upper estuary [23] extracted from the same image where the FV endmember was taken from (9 February 2016); MT) Moderate turbid waters extracted in the upper estuary when the turbidity maxima is expected in this region as described in Dogliotti et al. [31] (5 March 2017); DRG) highly reflective and turbid waters with values $~ 600$ FNU (see Figure 10), not usually found in this region and caused by intense dredging activity (17 August 2016); and XTW) extremely turbid waters ( $1800 \mathrm{FNU}$ ) extracted from the outer and most turbid part of the Río de la Plata Estuary, from a region called Punta Piedras (see [31]), on 1 May 2017.

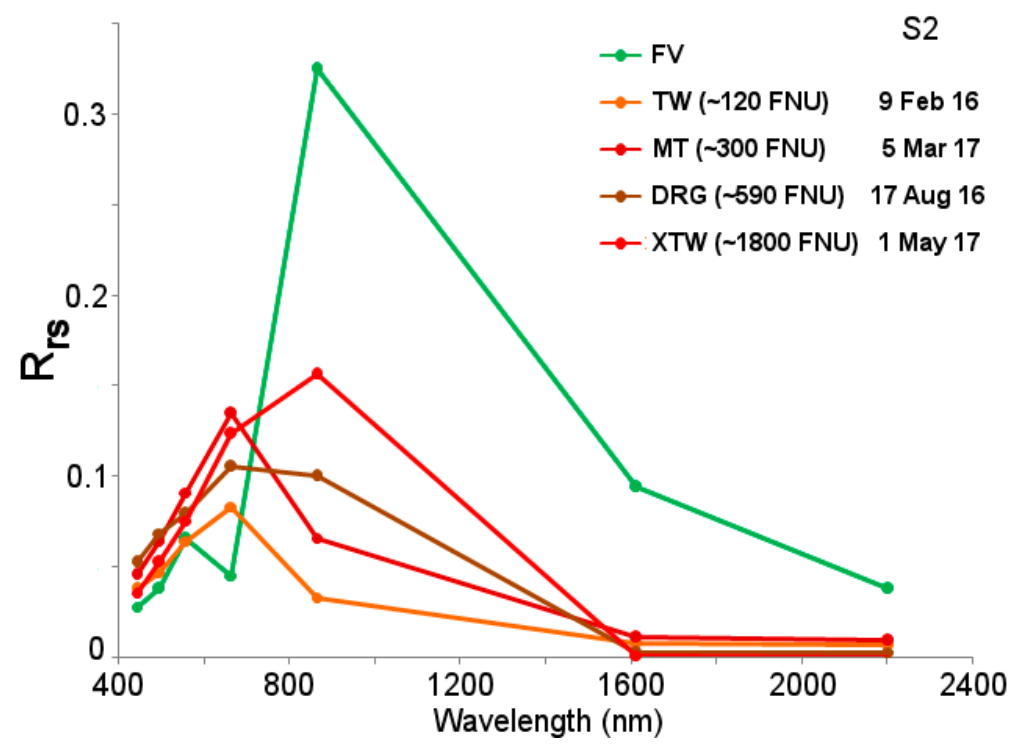

Figure 9. Spectra of selected endmembers of floating vegetation (FV), turbid waters (TW), moderate turbid waters (MT), highly turbid waters caused by intense dredging activity (DRG), and extreme turbid waters (XTW) extracted from different S2 images (only selected bands are shown). 

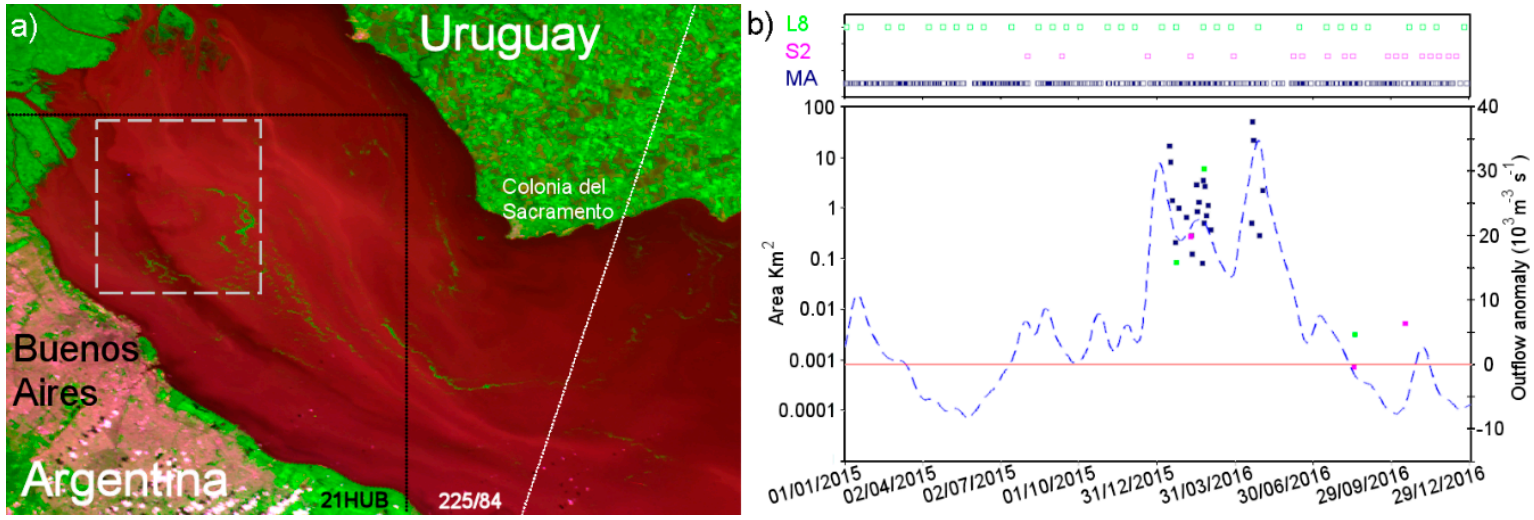

Figure 10. (a) Pseudo-true-color image of PROBA-V ( $R=650 \mathrm{~nm}, \mathrm{G}=835 \mathrm{~nm}, \mathrm{~B}=470 \mathrm{~nm})$ image $(100 \mathrm{~m})$ acquired on 22 April 2016 showing the region of interest (ROI) used for the FV area coverage analysis (grey dashed square), S2A 21HUB area (dotted-black line) and L8 225/84 path/row area (dotted white line). (b) FV area ( $\mathrm{km}^{2}$ ) detected by L8 (green), S2 (magenta), MA (blue) for the 2015-2016 time period overlaid over the RdP outflow anomaly (dashed light-blue line). Availability of non cloudy imagery for each sensor is shown on top.

The minimum percentage area of a pixel required to be detected as FV by the FAIT scheme (indicated in bold) and each of the indexes (FAI, RED and $\mathrm{La}^{*} \mathrm{~b}^{*}$ ) are listed in Table 2. The analysis showed that turbidity has a large effect on the ability to detect FV from ocean color imagery. It is clear that the FAI index cannot be used alone to detect floating vegetation given that turbidity can produce false positives which cannot be identified a priori. In this endmember mixing exercise the detection limit is $\sim 10 \%$ for typical and moderate turbid waters (Table 2), but for very turbid waters ( $>500 \mathrm{FNU}$ ) FAI would indicate the presence of FV even if FV is not present at all, confirming the need of additional conditions to avoid false positives. Consequently, the detection limit is mainly driven by the RED threshold, with a minimum of $\sim 60 \%$ of the pixel area needing to be covered for the moderately and extremely turbid waters and $\sim 40 \%$ for the particular condition of the dredging plume. For less and more typical turbid waters for this region ( 100 FNU), the "greenness" of the pixels is the condition that mainly determines the detection limit ( $28 \%)$. This further constraint, though more conservative, avoids false positives caused by cloud and boat edges (Figure 4) thus reducing the detection limit compared to FAI and RED thresholds.

Table 2. Values for the water $(100 \% \mathrm{~W})$ and FV $(0 \% \mathrm{~W})$ endmembers and the minimum percentage pixel area needed to detect floating vegetation (FV) for each condition (FAI index, RED threshold, $\mathrm{La}^{*} \mathrm{~b}^{*}$ color space metric) and FAIT scheme considering different water endmembers: turbid waters (TW), moderate turbid waters (MT), highly turbid waters from dredging activity (DRG), and extreme turbid waters (XTW). N/A: Not applicable.

\begin{tabular}{ccccccccccc}
\hline & & FAI & & & RED & & & La*b* $^{*}$ & & FAIT \\
& $\mathbf{1 0 0} \% \mathbf{W}$ & $\mathbf{0} \% \mathbf{W}$ & $\mathbf{M i n} \%$ & $\mathbf{1 0 0} \% \mathbf{W}$ & $\mathbf{0 \% W}$ & $\mathbf{M i n} \%$ & $\mathbf{1 0 0} \% \mathbf{W}$ & $\mathbf{0 \% W}$ & $\mathbf{M i n} \%$ & Min\% \\
\hline TW & -0.0336 & 0.2686 & 11.1 & 0.0834 & 0.043 & 9.1 & 10.6957 & -26.418 & 28.3 & $\mathbf{2 8 . 3}$ \\
MT & -0.0413 & 0.2686 & 13.4 & 0.1345 & 0.043 & 61.2 & 15.2198 & -26.418 & 51.8 & $\mathbf{6 1 . 2}$ \\
DRG & 0.0175 & 0.2686 & N/A & 0.1053 & 0.043 & 42.3 & 17.1252 & -26.418 & 40.0 & $\mathbf{4 2 . 3}$ \\
XTW & 0.0596 & 0.2686 & N/A & 0.1235 & 0.043 & 55.8 & 30.3149 & -26.418 & 56.2 & $\mathbf{5 6 . 2}$ \\
\hline
\end{tabular}

\subsection{Temporal Analysis of FV Coverage}

Given the significant impact that this event had on human activities in the capital city of Argentina, a region of interest (ROI $500 \mathrm{~km}^{2}$ ) close to Buenos Aires city was defined in order to evaluate the duration and spatial coverage of the floating vegetation invasion (dashed grey square in Figure 10a). 
A time series of MODIS/Aqua, Landsat-8/OLI and Sentinel-2/MSI images were processed for the 2015 and 2016 period in order to evaluate the algorithm for a year without (2015) and with (2016) floating vegetation. Given the large size of the estuary, L8 and S2 granules cover the estuary only partially (Figure 10a). Therefore, L8 (Path/Row $=225 / 84)$ and S2A $(21 \mathrm{HUB})$ granules were used and after visual inspection; only images with at least $10 \%$ of the ROI pixels with valid values (not clouded) were selected. The number of images analyzed and the estimated total area covered by FV during the 2015-2016 period in the ROI can be found in Table 3 and the temporal distribution of the images in Figure 10b (top). Fewer images were available and smaller total FV area were estimated for the higher spatial resolution sensors ( 0.3 and $5.8 \mathrm{Km}^{2}$ for S2A and L8, respectively) due to their reduced temporal resolution (Table 1 ) and given that the available images were often covered by clouds. It is noted that the reduced number of S2A images in 2015 was mainly due to the fact that it was launched in mid-June 2015 and images are available only since July 2015.

The first and last MODIS images that detected floating vegetation were acquired on 15 January and 3 May 2016, respectively. Between the 8 and 15 January 2016 there were no cloud-free images of the region, thus no exact date of the first detected floating vegetation can be determined. However, the first human observations of floating vegetation arriving to the coast of Buenos Aires were made on 16 January 2016 and the arrival of big masses was not continuous but in pulses after strong rains and thus cloudy days-for people in the city it may not be obvious why there is such intermittence, until viewing the satellite imagery where the spatial variability and downstream drift explains the observed temporal variability at the coast. Within this period the RdP outflow considerably increased due to heavy rains related to El Niño year. It can be clearly observed in Figure 10b that the occurrence of large FV area detected by MODIS coincided with the increase in outflow anomaly (dashed blue line). From August to the beginning of December 2016 L8 and S2A also detected a few pixels as FV, but these were not related to the floating vegetation invasion, but to the vegetation growing on a temporary island that was produced by increased dredging activity during this period and which is clearly observed in S2A RGB images (Figure 11).
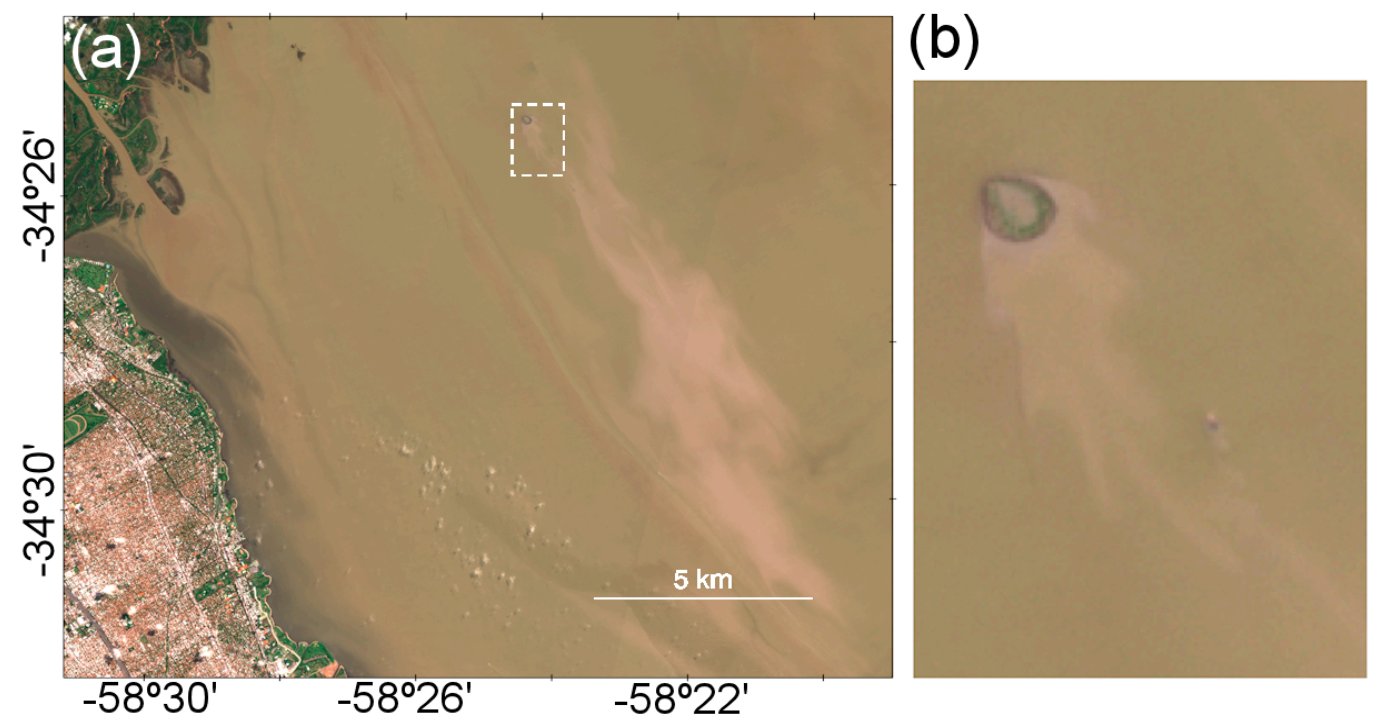

Figure 11. Quasi-true-color (RGB) Sentinel-2A image acquired on 16 October 2016. (a) A light-brown plume parallel to Buenos Aires' coastline produced by sediments after heavy dredging activities is clearly seen; and (b) a zoom (dashed square in [a]) shows the details of the temporarily vegetated island generated by the accumulation of sediments that this activity produced. 
Table 3. Total area covered by FV estimated summing over the number of FV pixels detected by each sensor for the 2015-2016 period in the region indicated in Figure 9 times the corresponding spatial resolution. The number of images used for $2015\left(\mathrm{~N}_{2015}\right)$ and $2016\left(\mathrm{~N}_{2016}\right)$ are also indicated.

\begin{tabular}{cccc}
\hline $\mathbf{N}$ & Total FV Area $\left(\mathbf{K m}^{\mathbf{2}}\right)$ & $\mathbf{N}_{\mathbf{2 0 1 5}}$ & $\mathbf{N}_{\mathbf{2 0 1 6}}$ \\
\hline MA & 114.0 & 185 & 158 \\
L8 & 5.8 & 17 & 15 \\
S2A & 0.3 & $3 *$ & 15 \\
\hline
\end{tabular}

* Sentinel-2A launched 23 June 2015.

\section{Conclusions}

The proposed methodology allows identifying and mapping the floating aquatic hyacinth (Eichhornia crassipes) invasion in the highly turbid RdP waters that started in January 2016. A combination of the FAI index (that makes use of the strong signal in the NIR portion of the spectrum), plus conditions set on the RED band (to avoid misclassifying highly turbid waters) and on the La* $b^{*}$ color space coordinates (to confirm the visually "green" pixels as FV) were used. One of the limitations of the presented method is that the FAI is not able to distinguish aquatic macrophytes from cyanobaterial scum given the similar response they have in the NIR region as has been already reported [26,32], which would produce false FV positives. For the specific 2016 event analyzed here, no cyanobacteria bloom have been reported in the upper estuary even though cyanobacteria blooms have been detected in different parts of the RdP coast since 1982 (Microcystis spp. and Anabaena spp. are the most common species). In general, large cyanobacteria blooms have been detected in the northern coast and outer part of the estuary in more clear waters [28]. In order to be able to have an automated global method to differentiate them sensors with higher spectral resolution are needed, for example bands at and around $\sim 620 \mathrm{~nm}$ would be useful given the characteristic pigment present in cyanobacteria cells called phicocyanin (PC), a phycobiliprotein that has a local absorption peak at $\sim 620 \mathrm{t} \mathrm{nm}$. Qi et al. [33] has already proposed an algorithm using MERIS $620 \mathrm{~nm}$ band to estimate PC blooms, in which both cyanobacteria cells and scum were detected and considered as bloom. Thus, existing multiscpectral systems with this band like the Sentinel-2/MSI, and possible future hyperspectral satellite missions like the HyspIRI, would provide essential information for improving the capability to map FV unambiguously and more accurately with no need of field data. Currently, the main limitation of Sentinel-2 data is the reduced temporal resolution, as has been pointed out in the present study. For this 2016 event, MODIS-250 m daily images allowed us to determine the period that the floating vegetation lasted ( $\sim 5$ months) and to make a coarse quantification of its extension. However, higher spatial resolution sensors, like Landsat- 8 and Sentinel-2, had the capability to detect finer-scale features and to better quantify the extent of floating vegetation despite their lower sensitivity compared to the coarser MODIS-250 m bands. It has been shown that the capability of detecting FV depends strongly on the turbidity of the water, with a detection limit (minimum \% of the S2-10 m pixel covered by FV) of $\sim 30 \%$ for turbid ( $10 \mathrm{NU}$ ), $\sim 60 \%$ for moderate to extreme turbid ( $>500 \mathrm{FNU}$ ) waters. Results indicate that both high spatial and temporal resolutions are needed to improve detection and quantification of FV, but the synergistic multimission use of available satellite, like in the present study, can provide useful information as well. Further improvement in temporal resolution has already been achieved with the recent launch of Sentinel-2B in March 2017, improving the revisit frequency from 10 to 5 days in cloud-free conditions and up to 2 or 3 days if the area of interest is covered by adjacent passes.

Author Contributions: A.I.D. obtained and processed the satellite and in situ data, developed the algorithm and wrote the manuscript; J.I.G. contributed to collect in situ data and to the algorithm development; Q.V. and K.G.R. contributed to the discussion and gave valuable suggestions to improve the manuscript. All authors approved the submitted manuscript. 
Funding: This research was funded by BELSPO (Belgian Federal Science Policy Office) HYPERMAQ (SR/00/335) and TURBINET (BL/58/FWI10) contracts, and by the ANPCyT PICT 2014-0455, and the CONICET PIP 112 20120100350 Projects.

Acknowledgments: The authors would like to thank Juan Borus (INA) for the Río de la Plata outflow data. USGS, NASA, and ESA are acknowledged for the Landsat-8, MODIS-Aqua, and Sentinel-2 imagery. The three anonymous reviewers are acknowledged for their useful comments.

Conflicts of Interest: The authors declare no conflict of interest.

\section{References}

1. Marchetti, Z.Y.; Latrubesse, E.M.; Pereira, M.S.; Ramonell, C.G. Vegetation and its relationship with geomorphologic units in the Parana River floodplain, Argentina. J. S. Am. Earth Sci. 2013, 46, 122-136. [CrossRef]

2. Fusilli, L.; Collins, M.O.; Laneve, G.; Palombo, A.; Pignatti, S.; Santini, F. Assessment of the abnormal growth of floating macrophytes in Winam Gulf (Kenya) by using MODIS imagery time series. Int. J. Appl. Earth Obs. Geoinform. 2013, 20, 33-41. [CrossRef]

3. Everitt, J.H.; Alaniz, M.A.; Davis, M.R. Using spatial information technologies to detect and map waterhyacinth and hydrilla infestations in the Lower Rio Grande. J. Aquat. Plant Manag. 2003, 41, 93-98.

4. Cohen, A.N.; Carlton, J.T. Accelerating invasion rate in a highly invaded estuary. Science 1998, 279, 555-558. [CrossRef] [PubMed]

5. Gower, J.; Hu, C.; Borstad, G.; King, S. Ocean color satellites show extensive lines of floating Sargassum in the Gulf of Mexico. IEEE Trans. Geosci. Remote Sens. 2006, 44, 3619-3625. [CrossRef]

6. $\mathrm{Hu}, \mathrm{C}$. A novel ocean color index to detect floating algae in the global oceans. Remote Sens. Environ. 2009, 113, 2118-2129. [CrossRef]

7. Shi, W.; Wang, M. Green macroalgae blooms in the YellowSea during the spring and summer of 2008. J. Geophys. Res. Oceans 2009, 114, C12010. [CrossRef]

8. Keesing, J.K.; Liu, D.; Fearns, P.; Garcia, R. Inter-and intra-annual patterns of Ulva prolifera green tides in the Yellow Sea during 2007-2009, their origin and relationship to the expansion of coastal seaweed aquaculture in China. Mar. Pollut. Bull. 2011, 62, 1169-1182. [CrossRef] [PubMed]

9. Alawadi, F. Detection of Surface Algal Blooms Using the Newly Developed Algorithm Surface Algal Bloom Index (SABI). In Proceedings of the SPIE Remote Sensing of the Ocean, Sea Ice, and Large Water Regions 2010, Toulouse, France, 20-23 September 2010; Volume 7825, p. 782506.

10. Xing, Q.; Hu, C. Mapping macroalgal blooms in the Yellow Sea and East China Sea using HJ-1 and Landsat data: Application of a virtual baseline reflectance height technique. Remote Sens. Environ. 2016, 178, 113-126. [CrossRef]

11. Hu, L.; Hu, C.; HE, M. Remote estimation of biomass of Ulva prolifera macroalgae in the Yellow Sea. Remote Sens. Environ. 2017, 192, 217-227. [CrossRef]

12. Hu, C.; Feng, L.; Hardy, R.F.; Hochberg, E.J. Spectral and spatial requirements of remote measurements of pelagic Sargassum macroalgae. Remote Sens. Environ. 2015, 167, 229-246. [CrossRef]

13. Liang, Q.; Zhang, Y.; Ma, R.; Loiselle, S.A.; Li, J.; Hu, M. A MODIS-Based Novel Method to Distinguish Surface Cyanobacterial Scums and Aquatic Macrophytes in Lake Taihu. Remote Sens. 2017, 9, 133. [CrossRef]

14. Minotti, P.; Ramonell, C.; Kandus, P. Regionalización del Corredor Fluvial Paraná-Paraguay. In Inventario de los Humedales de Argentina: Sistemas de Paisajes de Humedales del Corredor FluvialParaná-Paraguay, 1st ed.; Benzaquén, L., Blanco, D.E., Bó, R.F., Kandus, P., Lingua, G.F., Minotti, P., Quintana, R.D., Sverlij, S., Vidal, L., Eds.; Secretaría de Ambiente y Desarrollo Sustentable, Jefatura de Gabinete de Ministros de la Nación: Buenos Aires, Argentina, 2013; pp. 33-90, ISBN 978-987-29340-0-2.

15. World Water Assessment Programme. La Plata Basin Case Study. Final Report. UNESCO. Available online: unesdoc.unesco.org/images/0015/001512/151252e.pdf (accessed on 27 April 2018).

16. Robertson, A.W.; Mechoso, C.R. Interannual and decadal cycles in river flows of southeastern South America. J. Clim. 1998, 11, 2570-2581. [CrossRef]

17. Jaime, P.R.; Menéndez, A.N. Análisis del Régimen Hidrológico de Los Ríos Paraná y Uruguay. Informe LHA-01-216-02; INA, 1997. Available online: https:/ / www.ina.gov.ar/legacy/pdf/LH-Info_FRE_LHA-01216-02_FrePlata-ParanaUruguay_Jun_2002.pdf (accessed on 27 April 2018). 
18. Neiff, J.J.; Malvárez, I. Grandes Humedales Fluviales. In Bases Ecológicas Para la Clasificación e Inventario de Humedales en Argentina, 1st ed.; Malvárez, I., Bó, R.F., Eds.; FCEN; Universidad de Buenos Aires; RAMSAR; USFWS; USDS: Buenos Aires, Argentina, 2004; pp. 77-93.

19. Bó, R.F. Situación Ambiental en la Ecorregión Delta e Islas del Paraná. In Situación Ambiental en la Argentina 2005, 1st ed.; Brown, A., Martínez Ortiz, U., Acerbi, M., Corcuera, J., Eds.; Fundación Vida Silvestre Argentina: Buenos Aires, Argentina, 2016; pp. 131-143, ISBN 950-9427-14-4.

20. Neiff, J.J.; Iriondo, M.; Carignan, R. Large Tropical South American Wetlands: A Review; UNESCO Ecotones Workshop: Seattle, DC, USA, 1994; 15p.

21. Vanhellemont, Q.; Ruddick, K. Turbid wakes associated with offshore wind turbines observed with Landsat 8. Remote Sens. Environ. 2014, 145, 105-115. [CrossRef]

22. Vanhellemont, Q.; Ruddick, K. Advantages of high quality SWIR bands for ocean colour processing: Examples from Landsat-8. Remote Sens. Environ. 2015, 161, 89-106. [CrossRef]

23. Dogliotti, A.I.; Ruddick, K.G.; Nechad, B.; Doxaran, D.; Knaeps, E. A single algorithm to retrieve turbidity from remotely-sensed data in all coastal and estuarine waters. Remote Sens. Environ. 2015, 156, 157-168. [CrossRef]

24. Knaeps, E.; Ruddick, K.G.; Doxaran, D.; Dogliotti, A.I.; Nechad, B.; Raymaekers, D.; Sterckx, S. A SWIR based algorithm to retrieve Total Suspended Matter in extremely turbid waters. Remote Sens. Environ. 2015, 168, 66-79. [CrossRef]

25. Kou, L.; Labrie, D.; Chylek, P. Refractive indices of water and ice in the 0.65-2.5 $\mu \mathrm{m}$ spectral range. Appl. Opt. 1993, 32, 3531-3540. [CrossRef] [PubMed]

26. Hu, C.; Lee, Z.; Ma, R.; Yu, K.; Li, D.; Shang, S. Moderate resolution imaging spectroradiometer (MODIS) observations of cyanobacteria blooms in Taihu Lake, China. J. Geophys. Res. Oceans 2010, 115, C04002. [CrossRef]

27. CIE/ISO (Commission Internationale de l'Eclairage). Colorimetry_Part 5: CIE $1976 L^{*} u^{*} v^{*}$ Colour Space and u', v' Uniform Chromaticity Scale Diagram, 1st ed.; International Standard ISO/CIE: Geneva, Switzerland, 2016.

28. Dogliotti, A.I.; Gossn, J.I.; Vanhellemont, Q.; Ruddick, K. Large Invasion of Floating Aquatic Plants in the Río de la Plata Estuary! In Proceedings of the Ocean Optics XXIII Conference, Victoria, BC, Canada, 23-28 October 2016; Available online: http:/ / www.iafe.uba.ar/wordpress/filesMarine/Conferences/2016_ Dogliotti_etal_OO.pdf (accessed on 6 July 2018).

29. Cui, T.; Zhang, J.; Sun, L.; Jia, Y.; Zhao, W.; Wang, Z.; Meng, J. Satellitemonitoring of massive green macroalgae bloom (GMB): Imagingability comparison of multi-source data and drifting velocityestimation. Int. J. Remote Sens. 2012, 33, 5513-5527. [CrossRef]

30. Xu, Q.; Zhang, H.; Cheng, Y. Multi-sensor monitoring of Ulva prolifera blooms in the YellowSea using different methods. Front. Earth Sci. 2016, 10, 378-388. [CrossRef]

31. Dogliotti, A.I.; Ruddick, K.; Guerrero, R. Seasonal and inter-annual turbidity variability in the Río de la Plata from 15 years of MODIS: El Niño dilution effect. Estuar. Coast. Shelf Sci. 2016, 182, 27-39. [CrossRef]

32. Oyama, Y.; Matsushita, B.; Fukushima, T. Distinguishing surface cyanobacterial blooms and aquatic macrophytes using Landsat/TM and ETM+ shortwave infrared bands. Remote Sens. Environ. 2015, 157, 35-47. [CrossRef]

33. Qi, L.; Hu, C.; Duan, H.; Cannizzaro, J.; Ma, R. A novel MERIS algorithm to derive cyanobacterial phycocyanin pigment concentrations in a eutrophic lake: Theoretical basis and practical considerations. Remote Sens. Environ. 2014, 154, 298-317. [CrossRef]

(C) 2018 by the authors. Licensee MDPI, Basel, Switzerland. This article is an open access article distributed under the terms and conditions of the Creative Commons Attribution (CC BY) license (http:// creativecommons.org/licenses/by/4.0/). 